\title{
CARACTERIZAÇÃO DE VERMICOMPOSTO PRODUZIDO COM PALHA DE CAFÉ E ESTERCO BOVINO ${ }^{1}$
}

\author{
ALEX FAVARO NASCIMENTO ${ }^{2}$, FÁBIO RIBEIRO PIRES ${ }^{2 *}$, MARCIO PAULO CZEPAK ${ }^{2}$, ADRIANO ALVES \\ FERNANDES ${ }^{2}$, JOSÉ DE OLIVEIRA RODRIGUES ${ }^{2}$
}

\begin{abstract}
RESUMO - Apesar do conhecimento que se tem sobre os benefícios do húmus de minhoca ou vermicomposto há necessidade de se avaliar a viabilidade técnica de utilização de outras fontes de carbono para as minhocas. $\mathrm{O}$ objetivo do trabalho foi avaliar o efeito da palha de café associada ao esterco bovino para produção de vermicomposto sobre as minhocas e a qualidade do húmus obtido. Os tratamentos foram constituídos de: 1) Esterco Bovino 100\%; 2) Palha de Café 25\% + Esterco Bovino 75\%; 3) Palha de Café 50\% + Esterco Bovino 50\%; 4) Palha de Café 75\% + Esterco Bovino 25\%; e 5) Palha de Café 100\%. A palha de café e o esterco permaneceram incubados por 64 dias para que ficassem disponíveis para a alimentação das minhocas e mais 84 dias para digestão do substrato. A palha de café não interferiu no incremento populacional das minhocas. O aumento percentual da palha na constituição do vermicomposto aumentou a disponibilidade de $\mathrm{N}, \mathrm{K}, \mathrm{Ca}$ e $\mathrm{Cu}$, mas reduziu em P, Mg, S, Mn, Fe e Zn. Visando o fornecimento médio de nutrientes, a proporção de $50 \%$ de palha de café e $50 \%$ de esterco de bovino é a mais indicada.
\end{abstract}

Palavras-chave: Minhocas. Resíduos Orgânicos. Sustentabilidade.

\section{CHARACTERIZATION OF VERMICOMPOST PRODUCED WITH STRAW COFFEE AND CATTLE MANURE}

\begin{abstract}
Despite the knowledge that you have about the benefits of the humus of the worms or vermicompost, there is a need to evaluate the technical feasibility of using other sources of carbon for worms. The objective was to evaluate the possibility of using straw of coffee to vermicompost production, the effects of their use on worms and on the quality of humus obtained. The evaluated treatments consisted of: (1 straw of coffee (SC) $100 \% ; 2$ SC 75\% + manure (MA); 3 50\% SC + 50\% MA; 4 25\% SC + 75\% MA; 5 100\% MA). The straw of coffee and the manure were incubated for 64 days to make them available to feed the worms and more 84 days to digest the substrate. The straw of coffee increased the number of worms without resulting in harmful effects. The percentage increment of the straw in the constitution of the vermicompost increased the availability of $\mathrm{N}, \mathrm{K}, \mathrm{Ca}$ and $\mathrm{Cu}$, but it reduced the availability of $\mathrm{Mg}, \mathrm{S}, \mathrm{Mn}, \mathrm{P}, \mathrm{Fe}$ and $\mathrm{Zn}$. Aiming o the medium supply of nutrients, the proportion of the $50 \%$ of straw of coffee and $50 \%$ of manure is designated.
\end{abstract}

Keywords: Worms. Organic wastes. Sustainability.

\footnotetext{
*Autor para correspondência

${ }^{1}$ Recebido para publicação em 05/03/2014; aceito em 30/07/2015.

${ }^{2}$ Departamento de Ciências Agrárias e Biológicas, CEUNES/UFES, Rodovia BR 101 Norte, Km. 60, Bairro Litorâneo, 29932-540, São Mateus (ES); afavaronascimento@gmail.com, pires.fr@gmail.com, marcioczepak@gmail.com, afernandesufes@gmail.com, rodrigolajinha19@yahoo.com.br.
} 


\section{INTRODUÇ̃̃̃O}

A modernização da agricultura depende da grande variedade de insumos, fertilizantes e pesticidas e ainda é caracterizada pela intensificação da mecanização, o que afeta de maneira danosa o ambiente e a qualidade dos alimentos. Nesse contexto, a adubação orgânica surge como alternativa beneficiando características físicas e químicas do solo, como a melhoria da estrutura, com reflexos no aumento da permeabilidade e também na conservação da umidade, a liberação lenta e a solubilização de nutrientes para as plantas, a manutenção do poder tampão e da atividade biológica (SILVA; MENDONÇA, 2007; FERNANDES et al., 2013).

Sabe-se, contudo, que esses resíduos necessitam passar por etapas de reciclagem e processamento, podendo ser feito por minhocas em conjunto com a flora que vive em seu trato digestivo (LANDGRAF et al. 2005). Outrossim, a ação das minhocas promove a vermicompostagem ou vermiestabilização, ou seja, a transformação da matéria orgânica recente em matéria orgânica estabilizada (SILVA et al., 2011).

O papel das minhocas na decomposição de resíduos orgânicos tem sido demonstrado em várias pesquisas (MELO JÚNIOR et al., 2012; OLIVEIRA et al., 2013). A vermicompostagem é um sistema tecnológico reconhecido como de baixo custo (BASSACO et al, 2015), o qual pode ter alto valor nutricional para as plantas (MELO JÚNIOR et al., 2012), cujo efeito se dá em curto espaço de tempo (CAMPITELLI; CEPPI, 2008), reduzindo substancialmente o tempo de percurso entre a fotossíntese e o húmus (GARG; YADAY, 2011).

As minhocas ingerem a matéria orgânica transformando-a em coprólito, produto dessa digestão, contendo nutrientes em maior concentração que o solo. Isso ocorre em virtude do solo e o coprólito estarem agora misturados com matéria orgânica e secreções intestinais e urinárias, encontrando-se em estado mais avançado de decomposição, proporcionando uma produção acelerada de ácidos húmicos (OTHMAN et al., 2012). Essa aceleração decorre da ação das enzimas produzidas no tubo digestivo das minhocas e da atividade de microorganismos nele existentes (STEFFEN et al, 2011), como, por exemplos, bactérias, fungos, actinomicetos, algas e protozoários, grandemente estimulados, antes de serem excretados (MARTINEZ, 1995).

Dentro de seu trato digestivo o material do solo sofre transformações, havendo decomposição de matéria orgânica e disponibilidade de nutrientes para as plantas (FIGUEIREDO et al., 2012). O composto de minhoca aumenta a fertilidade do solo pelo aumento da oferta de nutrientes e pela melhoria das propriedades físicas do solo (LANDGRAF et al., 1999). Segundo Tagliari (1995), os excrementos de minhocas aumentaram de três a onze vezes o teor de fósforo assimilável, de potássio e magnésio trocáveis no solo e ainda elevaram de cinco a dez vezes o teor de nitratos e em $30 \%$ o de cálcio, reduzindo a acidez do solo. Em outro trabalho, observou-se aumento significativo nos teores de nitrogênio no lodo de esgoto nos tratamentos submetidos ao processo de vermicompostagem. O teor de nitrogênio total (N-total), após 48 dias submetido a ação das minhocas, aumentou de $24,5 \mathrm{mg} \mathrm{Kg}^{-1}$ para $43,17 \mathrm{mg} \mathrm{Kg}^{-1}$, o equivalente a 76,2\% de aumento (SILVA et al., 2011b).

Comparando a compostagem com a vermicompostagem, Dores-Silva et al. (2013) apresentam que a capacidade de troca cationica (CTC) teve tendência de aumento após os processos de compostagem e maior ainda após a vermicompostagem. Isso sugere que os coloides orgânicos do vermicomposto têm uma maior habilidade em adsorver cátions na solução do solo do que os compostos, podendo depois cedê-los ou efetuar trocas, caso ocorra uma concentração de íons diferente ou uma variação de $\mathrm{pH}$. Destacaram também nesse trabalho o aumento de nitrogênio total e fósforo total após os processos descritos. Uma mineralização mais intensa dos nutrientes também foi observada por Silva et al. (2013) após a vermicompostagem.

Para o teor de minerais presentes no vermicomposto podem ocorrer interações de acordo com a origem do esterco e espécie de minhoca. Rodrigues et al. (2003), em estudo da composição mineral do vermicomposto de esterco proveniente de bubalinos e bovinos, relatam que a maior porcentagem de nitrogênio e cobre foi observada para o vermicomposto procedente de bovino com minhoca Vermelha. Já para os teores de potássio observou-se que as melhores combinações seriam de vermicomposto derivado de búfalo com minhoca Africana ou de bovino com minhoca Vermelha.

A vermicultura pode ser utilizada com a finalidade de atender a reciclagem de resíduos orgânicos urbanos, lixo e esgoto (ANTONIOLLI, 2004; SILVA et al., 2011a), e resíduos agroindustriais, como os de frigoríficos, laticínios, indústrias de conserva e extração de sucos, curtumes, bagaço de uvas, resíduos de cana-de-açúcar e de mostarda, esterco de suínos, ovinos, equinos e coelhos (SILVA et al., 2011b).

A utilização de matérias-primas alternativas ao esterco animal na composição do vermicomposto é de grande relevância, principalmente os de origem vegetal (CUNHA et al., 2014). Resíduos agroindustriais são potencialmente interessantes e abundantes e sua utilização reduz o impacto ambiental decorrente de sua deposição incorreta (BASSACO et al., 2015).

No entanto, apesar do conhecimento que se tem sobre os seus possíveis benefícios há necessidade de se avaliar a viabilidade técnica de utilização de outras fontes de carbono para as minhocas, ou seja, os possíveis efeitos sobre elas e sobre a qualidade do composto obtido.

Assim, objetivou-se avaliar a densidade populacional de minhocas e a qualidade nutricional do

Revista Caatinga, Mossoró, v. 28, n. 4, p. 1 - 9, out. - dez., 2015 
composto produto da vermicompostagem em combinações de palha de café e esterco bovino.

\section{MATERIAL E MÉTODOS}

O experimento foi conduzido de setembro de 2007 a janeiro de 2008 no Sítio São Lázaro, localizado no município de São Mateus (ES), a 39 metros de altitude. Sua posição geográfica é determinada pelo paralelo $18^{\circ} 43^{\prime}$ de latitude ao Sul e sua interseção com o meridiano de $39^{\circ} 51^{\prime}$ de longitude oeste (ESTAÇÃO METEOROLÓGICA - São Mateus A616, 2012).

As unidades experimentais foram constituídas por canteiros de alvenaria, com dimensões de 1,0 m de comprimento x $1,0 \mathrm{~m}$ de largura $\times 0,5 \mathrm{~m}$ de profundidade. $\mathrm{O}$ delineamento experimental foi em blocos ao acaso com quatro repetições em esquema de parcelas subdivididas no tempo (avaliação no início e no final). Os compostos orgânicos do trabalho foram obtidos pela mistura de esterco bovino + palha de café totalizando $62 \mathrm{~kg}$ por parcela, tendo como tratamentos: 1) Esterco Bovino 100\%; 2) Palha de Café 25\% + Esterco Bovino 75\%; 3) Palha de Café $50 \%$ + Esterco Bovino 50\%; 4) Palha de Café 75\% + Esterco Bovino 25\% e 5) Palha de Café 100\%. E determinados com base na massa de cada componente na mistura, cuja umidade foi aferida com o mesmo valor para todos.

Os tratamentos passaram por um período de incubação necessário para que atingissem o ponto adequado para a alimentação das minhocas, o que ocorreu aos 64 dias quando a temperatura atingiu 28 a $30{ }^{\circ} \mathrm{C}$, de acordo com Tagliari (1995). Para acelerar a fermentação, o material foi revolvido e umedecido periodicamente em quantidade suficiente para manter o substrato com umidade a $60 \%$ da capacidade de campo (CC). A temperatura também foi monitorada nesse período de incubação. Posteriormente, de acordo com o sistema de isca definido por Ávila (1999), foram inoculadas em cada tratamento 1500 minhocas da espécie Eisenia foetida Savingy - 1826, também conhecidas como minhoca Vermelha da Califórnia ou minhoca do esterco, provenientes do próprio minhocário. $\mathrm{O}$ material foi recoberto com uma camada de folhas secas de mangueiras visando diminuir a evaporação de água. O tempo médio para digestão do substrato foi de 84 dias, tomando-se como referência o tempo em que as minhocas levaram para atingir a base do canteiro. Cabe salientar que esse critério foi atingido pelos tratamentos $0 \%, 25 \%$ e $50 \%$ de palha de café.

Foram avaliadas no início e final do experimento a população e massa fresca das minhocas, volume e massa do substrato. Também foi feita a análise química do vermicomposto (inicial e final), na qual foram determinados os teores totais dos macronutrientes $\mathrm{N}, \mathrm{P}, \mathrm{K}, \mathrm{Ca}, \mathrm{Mg}, \mathrm{S}$, e dos micronutrientes $\mathrm{Fe}, \mathrm{Mn}, \mathrm{Cu}$ e $\mathrm{Zn}$, segundo metodologia proposta pela Embrapa (2009).

Os dados foram submetidos a análise de variância e comparados pelo teste de Tukey a 5\% de probabilidade. Os efeitos significativos dos tratamentos envolvendo o percentual de palha de café no vermicomposto foram submetidos a análise de regressão, sendo os coeficientes das equações testados pelo teste " $t$ ".

\section{RESULTADOS E DISCUSSÃO}

Durante a compostagem fora verificado que a quantidade de água demandada por cada tratamento aumentou de acordo com o aumento da porcentagem de palha de café no composto (Tabela 1). Isso ocorreu porque a palha de café possui uma relação $\mathrm{C} / \mathrm{N}$ maior que o esterco bovino, exigindo mais água para sua decomposição e controle da temperatura (SOUZA; REZENDE, 2006).

Tabela 1. Quantidade total de água consumida durante o período de incubação do substrato pelos tratamentos compostos, pelas combinações de palha de café e esterco bovino.

\begin{tabular}{cc}
\hline Tratamentos & Água demandada (L) \\
\hline EC $100 \%$ & 145 \\
EC $75 \%+$ PC $25 \%$ & 180 \\
EC $50 \%+$ PC $50 \%$ & 220 \\
EC $25 \%+$ PC $75 \%$ & 260 \\
PC $100 \%$ & 300 \\
\hline
\end{tabular}

A temperatura, após a incubação, aumentou consideravelmente nos primeiros 15 dias proporcional ao aumento da porcentagem de palha de café no composto e depois decresceu, ao final do processo, até aproximadamente $27{ }^{\circ} \mathrm{C}$ em média (Figura 1). Isso ocorreu devido ao aumento do teor de carbono orgânico que facilita o desenvolvimento dos microorganismos termofílicos, responsáveis pela elevação das temperaturas e a aceleração do processo de degradação dos resíduos orgânicos (SARDÁ et al.,
2010; CARLESSO et al., 2011). A queda posterior da temperatura ocorre pela diminuição da atividade dos microorganismos. Em seguida, ocorre fase de maturação ou humificação em que as temperaturas se situam entre $20^{\circ}$ e $35^{\circ} \mathrm{C}$ (MMA, 2010).

A população final de minhocas não apresentou diferença significativa entre os tratamentos, com média de 8.491 minhocas. Todavia, pelo teste de Tukey a $5 \%$ de probabilidade, diferiu do valor inicial de 1500 minhocas por tratamento (Tabela 2). Isso 
indica que independentemente do percentual de palha de café na mistura com esterco a proliferação das minhocas foi favorecida, provavelmente pela libera- ção de nutrientes do material incubado e pela ampla disponibilidade de fonte de carbono (CALONEGO et al., 2012; ZOCA, 2012).

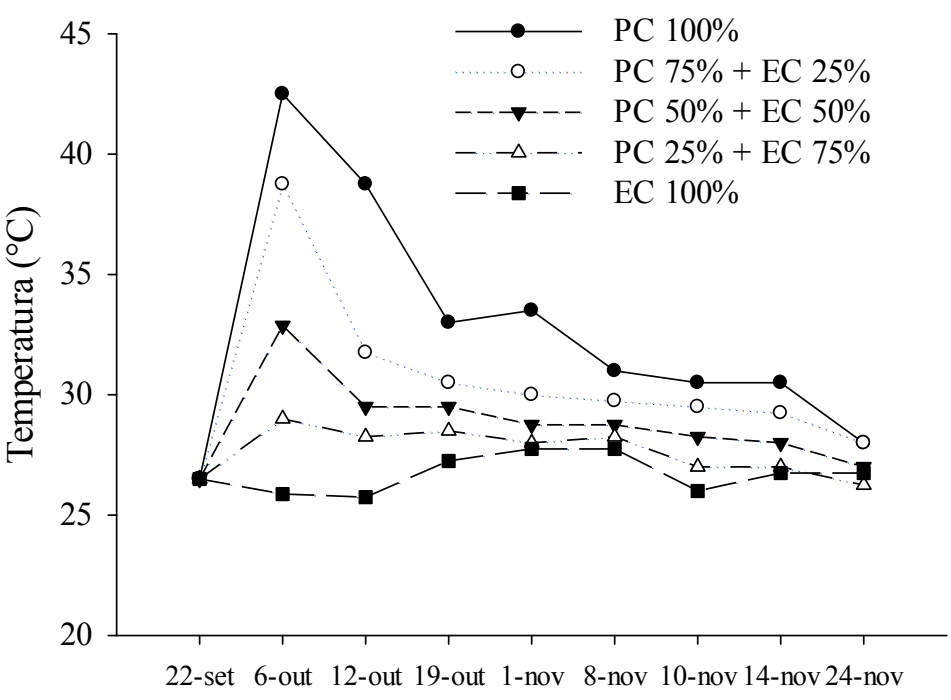

Tempo

Figura 1. Evolução das temperaturas médias dos tratamentos durante o tempo de incubação da palha de café.

Tabela 2. Número de minhocas e teor de K no substrato avaliados no início e no final do período de incubação em diferentes percentuais de palha de café utilizada na produção de vermicomposto.

\begin{tabular}{ccc}
\hline Avaliação & Número de Minhocas/parcela & $\mathrm{K}\left(\mathrm{dag} \mathrm{kg}^{-1}\right)$ \\
\hline Início & $1500 \mathrm{~b}$ & $2,16 \mathrm{a}$ \\
\hline Final & $8491 \mathrm{a}$ & $1,74 \mathrm{~b}$ \\
\hline
\end{tabular}

*Médias seguidas de mesma letra na coluna não diferem entre si pelo teste de Tukey a 5\%.

A massa média das minhocas, obtida no dia da inoculação e após o período de tempo para digestão, 84 dias, não apresentou variação significativa entre os tratamentos, com média de $0,1399 \mathrm{~g}$ (dados não apresentados). A palha de café não proporcionou ganho de massa para as minhocas. Esses resultados diferem dos obtidos por Pereira et al. (2005), que utilizando como substrato esterco bovino e palha de carnaúba, obtiveram redução do peso fresco e seco das minhocas na medida em que se aumentou a quantidade de palha.

A altura, o volume e a massa do substrato diminuíram significativamente após o processo de humificação (Tabela 3). Isso se deve às transformações sofridas pelo material, no qual ocorreu redução da porosidade e perda de carbono na forma de $\mathrm{CO}_{2}$, explicada pela mineralização do substrato e pela atividade respiratória das minhocas e dos microrganismos (TRIPATHI; BHARDWAJ, 2004). Observa-se também que houve aumento da altura e volume do substrato na medida em que se aumentou a porcentagem de palha de café, o que se deve à menor densidade desse material em relação ao esterco bovino (Figuras 2a e 2b). Contudo, em relação a massa do substrato, não foi observada alteração significativa (Figura 2c).
Considerando a composição química antes e depois da compostagem para o tratamento com $100 \%$ de palha de café observou-se que N e S apresentaram um aumento significativo do início para o final do período de avaliação (Tabela 3), com aumentos de 30,6 e $42,10 \%$, respectivamente. Com o aumento da porcentagem de palha de café foi observada uma tendência do aumento da concentração de nitrogênio e uma redução da concentração de enxofre. Para o N, o resultado foi semelhante ao observado por Silva et al. (2002), que verificaram aumento significativo de $\mathrm{N}$ de aproximadamente $70 \%$, confirmando a capacidade das minhocas em imobilizar nitrogênio. Isso ocorreu durante o processo de mineralização e respiração, tanto dos microorganismos quanto das minhocas, na qual a matéria orgânica evoluiu, em parte, para $\mathrm{CO}_{2}$, havendo dessa maneira uma concentração dos macro e micronutrientes, no caso específico relatado do N (DORES-SILVA et al., 2011). Esse acréscimo também se dá em razão dos excrementos das minhocas, que são ricos em nitrogênio e oriundos do próprio corpo destes anelídeos, os quais liberam expressiva quantidade deste nutriente quando morrem (BATTIROLA et al., 1998). Como o $\mathrm{N}$ é um dos nutrientes essenciais para o crescimento e desenvolvimento das plantas e um insumo de elevado custo, essa constatação aponta um aspecto alta- 
mente positivo do vermicomposto para reduzir o custo de produção. O enxofre, porém, exibiu comportamento contrário, ou seja, apresentou maior disponibilidade com o aumento da porcentagem de esterco bovino (Figura 3), o que pode ser explicado pelo maior teor de enxofre na composição dos estercos (SILVA et al., 2014). De acordo com Menezes e
Da Silva (2008), a adição de matéria orgânica no solo é capaz não apenas de garantir a manutenção de níveis adequados de enxofre no solo, como também elevar com o tempo significativamente esses níveis. $\mathrm{O}$ enxofre pode aumentar o teor foliar conforme se aumentam as doses de esterco bovino (COSTA; VALERI, 2012).

Tabela 3. Altura, volume e massa do substrato e teores de $\mathrm{N}, \mathrm{P}, \mathrm{K}, \mathrm{Ca}, \mathrm{Mg}, \mathrm{S}$ e $\mathrm{Fe}, \mathrm{Mn}, \mathrm{Cu}$ e $\mathrm{Zn}$ avaliados no início e final da vermicompostagem por minhocas em função do percentual de palha de café.

\begin{tabular}{|c|c|c|c|c|c|}
\hline \multirow[b]{2}{*}{ Avaliação } & \multicolumn{5}{|c|}{ \% Palha de café na composição do vermicomposto } \\
\hline & 0 & 25 & 50 & 75 & 100 \\
\hline \multicolumn{6}{|c|}{ Altura do Substrato (m) } \\
\hline Inicial & $0,08 \mathrm{a}$ & $0,12 \mathrm{a}$ & $0,13 \mathrm{a}$ & $0,17 \mathrm{a}$ & $0,22 \mathrm{a}$ \\
\hline Final & $0,06 \mathrm{~b}$ & $0,08 \mathrm{~b}$ & $0,09 \mathrm{~b}$ & $0,11 \mathrm{~b}$ & $0,15 \mathrm{~b}$ \\
\hline \multicolumn{6}{|c|}{ Volume do substrato $\left(\mathrm{dm}^{3}\right)$} \\
\hline Inicial & $79,50 \mathrm{a}$ & $117,50 \mathrm{a}$ & $130,75 \mathrm{a}$ & $173,75 \mathrm{a}$ & $217,50 \mathrm{a}$ \\
\hline Final & $59,25 \mathrm{~b}$ & $75,00 \mathrm{~b}$ & $87,00 \mathrm{~b}$ & $111,50 \mathrm{~b}$ & $148,25 \mathrm{~b}$ \\
\hline \multicolumn{6}{|c|}{ Massa do substrato $(\mathrm{kg})$} \\
\hline Inicial & $46,58 \mathrm{a}$ & $56,14 \mathrm{a}$ & 53,76 a & $57,40 \mathrm{a}$ & $57,94 \mathrm{a}$ \\
\hline Final & $36,96 \mathrm{~b}$ & $38,12 \mathrm{~b}$ & $31,09 \mathrm{~b}$ & $30,16 \mathrm{~b}$ & $33,43 \mathrm{~b}$ \\
\hline \multicolumn{6}{|c|}{ Nitrogênio $\left(\right.$ dag kg $\left.{ }^{-1}\right)$} \\
\hline Inicial & $2,45 \mathrm{a}$ & $2,84 \mathrm{a}$ & 3,06 a & $3,28 \mathrm{a}$ & $3,30 \mathrm{~b}$ \\
\hline Final & $2,14 \mathrm{a}$ & $3,00 \mathrm{a}$ & $3,43 \mathrm{a}$ & $3,39 \mathrm{a}$ & $4.31 \mathrm{a}$ \\
\hline \multicolumn{6}{|c|}{ Fósforo $\left(\right.$ dag $\left.\mathrm{kg}^{-1}\right)$} \\
\hline Inicial & $0,48 \mathrm{a}$ & 0,40 a & $0,34 \mathrm{a}$ & 0,24 a & $0,16 \mathrm{a}$ \\
\hline Final & $0,48 \mathrm{a}$ & $0,39 \mathrm{a}$ & $0,33 \mathrm{a}$ & $0,22 \mathrm{a}$ & $0,18 \mathrm{a}$ \\
\hline \multicolumn{6}{|c|}{ Potássio $\left(\mathrm{dag} \mathrm{kg}^{-1}\right)$} \\
\hline Inicial & $0,92 \mathrm{a}$ & $1,77 \mathrm{a}$ & $2,29 \mathrm{a}$ & $2,85 \mathrm{a}$ & $2,98 \mathrm{a}$ \\
\hline Final & $0,48 \mathrm{~b}$ & $1,02 \mathrm{~b}$ & $2,07 \mathrm{a}$ & $2,36 \mathrm{~b}$ & $2,76 \mathrm{a}$ \\
\hline \multicolumn{6}{|c|}{ Cálcio (dag kg-1 } \\
\hline Inicial & $0,71 \mathrm{a}$ & $0,78 \mathrm{~b}$ & $0,82 \mathrm{~b}$ & $0,87 \mathrm{~b}$ & $0,81 \mathrm{~b}$ \\
\hline Final & $0,72 \mathrm{a}$ & $0,88 \mathrm{a}$ & $1.02 \mathrm{a}$ & $1,05 \mathrm{a}$ & $1.06 \mathrm{a}$ \\
\hline \multicolumn{6}{|c|}{ Magnésio (dag kg $\left.{ }^{-1}\right)$} \\
\hline Inicial & $0,44 \mathrm{a}$ & $0,40 \mathrm{a}$ & $0,35 \mathrm{~b}$ & $0,25 \mathrm{~b}$ & $0,17 \mathrm{~b}$ \\
\hline Final & $0,41 \mathrm{~b}$ & $0,41 \mathrm{a}$ & $0,38 \mathrm{a}$ & $0,30 \mathrm{a}$ & $0,23 \mathrm{a}$ \\
\hline \multicolumn{6}{|c|}{ Enxofre $\left(\right.$ dag kg $\left.^{-1}\right)$} \\
\hline Inicial & $0,45 \mathrm{a}$ & $0,45 \mathrm{a}$ & $0,37 \mathrm{a}$ & $0,28 \mathrm{a}$ & $0,19 \mathrm{~b}$ \\
\hline Final & $0,40 \mathrm{a}$ & $0,38 \mathrm{~b}$ & $0,39 \mathrm{a}$ & $0,33 \mathrm{a}$ & $0,27 \mathrm{a}$ \\
\hline
\end{tabular}

*Médias seguidas de mesma letra minúscula na coluna não diferem entre si pelo teste de Tukey a $5 \%$.
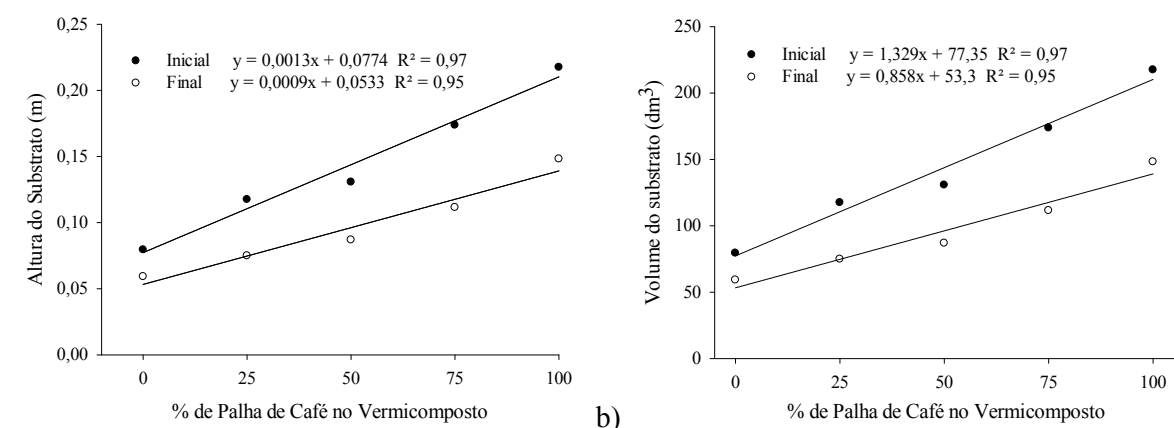

a)

b)



Figura 2. Altura, volume e massa do substrato avaliados no início e final do período de incubação em função do percentual de palha de café utilizado na produção de vermicomposto.

Revista Caatinga, Mossoró, v. 28, n. 4, p. 1 - 9, out. - dez., 2015 

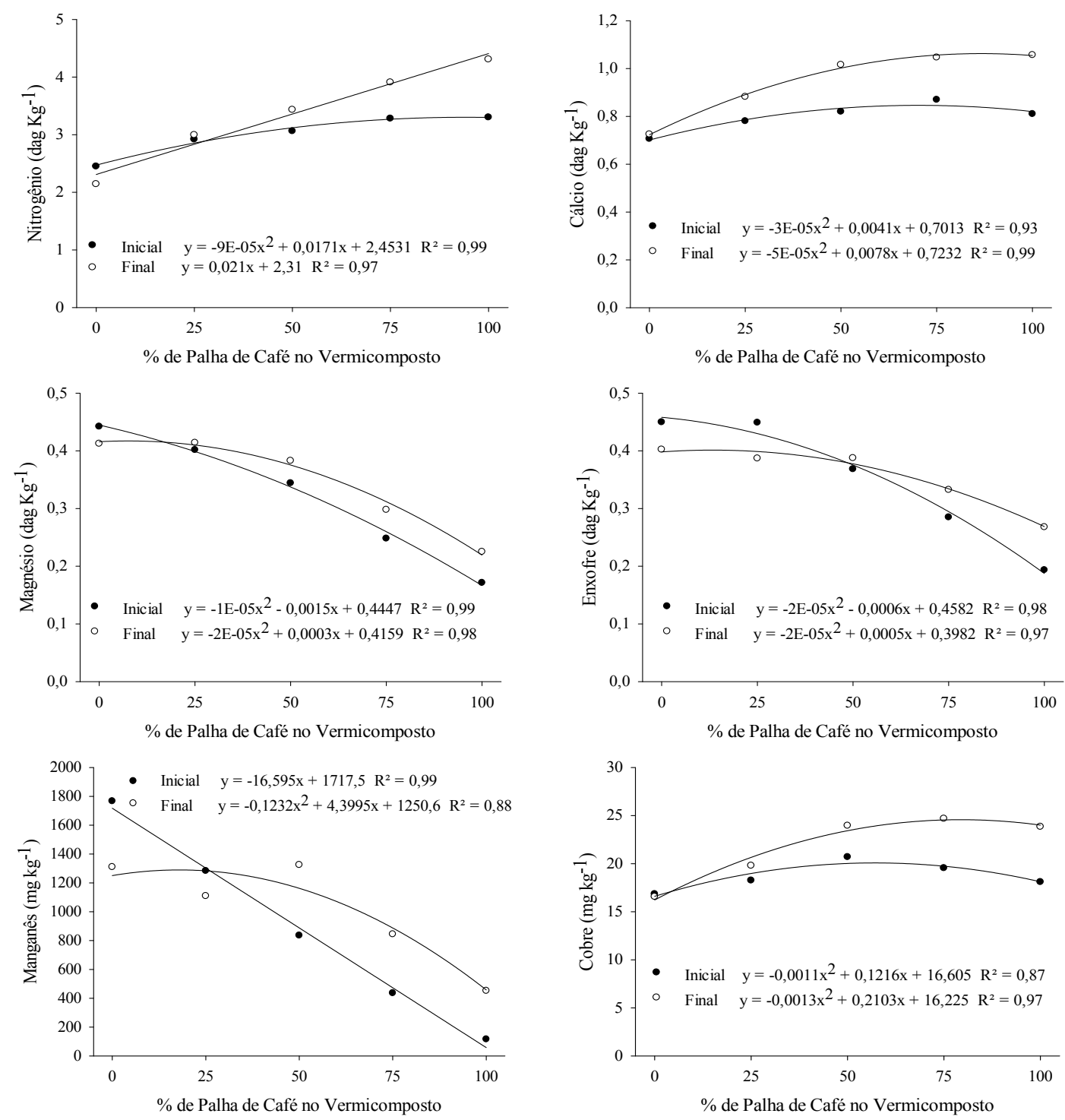

Figura 3. Teores de $\mathrm{N}, \mathrm{Ca}, \mathrm{Mg}, \mathrm{S}, \mathrm{Mn}$ e $\mathrm{Cu}$ no substrato avaliados no início e final do período de incubação em função do percentual de palha de café utilizada na produção de vermicomposto.

A partir da composição com $50 \%$ de palha de café, os teores de $\mathrm{Ca}$ e $\mathrm{Mg}$ (Tabela 3) e $\mathrm{Cu}$ (Tabela 4) apresentaram aumento dos valores finais em relação ao início da digestão, resultado de uma maior disponibilização desses elementos pelos anelídeos. Os resultados concordam com os de Tagliari (1995) para $\mathrm{Ca}$ e Suszek (2005) para $\mathrm{Cu}$, tendo este último observado aumento, principalmente para os tratamentos com maiores concentrações de esterco bovino. $\mathrm{O}$ aumento do percentual de palha no vermicomposto até $75 \%$ promoveu acúmulo de $\mathrm{Cu}$, observando -se posterior queda no nível com $100 \%$ de palha (Figura 3). Ao contrário, as concentrações de $\mathrm{Mg}$ diminuíram com o aumento percentual da palha de café (Figura 3). Os elementos P (Tabela 3), Fe e Zn (Tabela 4) não apresentaram variação entre as duas avaliações.

$\mathrm{O}$ teor de potássio $\mathrm{K}$ reduziu no substrato, do início para o final do período de avaliação (Tabela 2), o que pode ser atribuído à lixiviação daquele no canteiro, haja vista o mesmo apresentar elevada lixiviação (DUARTE et al., 2013). Apesar disso, constatou-se acréscimo na concentração de $\mathrm{K}$ com o aumento da quantidade de palha (Figura 4) decorrente do elevado acúmulo que ocorre deste mineral na palha de café (ZOCA, 2012). 
A. F. NASCIMENTO et al.

Tabela 4. Teores de $\mathrm{Fe}, \mathrm{Mn}, \mathrm{Cu}$ e $\mathrm{Zn}$ avaliados no início e final da vermicompostagem por minhocas em função do percentual de palha de café.

\begin{tabular}{cccccc}
\hline \multicolumn{7}{c}{ Ferro $\left(\mathrm{mg} \mathrm{kg}^{-1}\right)$} \\
\hline Inicial & $10986,90 \mathrm{a}$ & $8747,75 \mathrm{a}$ & $6210,43 \mathrm{a}$ & $2567,23 \mathrm{a}$ & $629,05 \mathrm{a}$ \\
Final & $11501,53 \mathrm{a}$ & $8430,53 \mathrm{a}$ & $6296,78 \mathrm{a}$ & $3240,95 \mathrm{a}$ & $976,40 \mathrm{a}$ \\
\hline \multicolumn{7}{c}{ Manganês $\left(\mathrm{mg} \mathrm{kg}^{-1}\right)$} \\
\hline Inicial & $1767,05 \mathrm{a}$ & $1283,44 \mathrm{a}$ & $835,83 \mathrm{a}$ & $436,35 \mathrm{a}$ & $116,23 \mathrm{a}$ \\
Final & $1310,58 \mathrm{a}$ & $928,15 \mathrm{a}$ & $1325,15 \mathrm{a}$ & $844,65 \mathrm{a}$ & $452,40 \mathrm{a}$ \\
\hline \multicolumn{7}{c}{ Zinco $\left(\mathrm{mg} \mathrm{kg}^{-1}\right)$} \\
\hline Inicial & $104,35 \mathrm{a}$ & $75,85 \mathrm{a}$ & $49,10 \mathrm{a}$ & $23,60 \mathrm{a}$ & $14,03 \mathrm{a}$ \\
Final & $104,15 \mathrm{a}$ & $75,58 \mathrm{a}$ & $51,53 \mathrm{a}$ & $25,15 \mathrm{a}$ & $22,65 \mathrm{a}$ \\
\hline \multicolumn{7}{c}{ Cobre $\left(\mathrm{mg} \mathrm{kg}^{-1}\right)$} \\
\hline Inicial & $16,88 \mathrm{a}$ & $18,28 \mathrm{a}$ & $20,70 \mathrm{~b}$ & $19,57 \mathrm{~b}$ & $18,13 \mathrm{~b}$ \\
Final & $16,58 \mathrm{a}$ & $19,83 \mathrm{a}$ & $24,00 \mathrm{a}$ & $24,70 \mathrm{a}$ & $23,88 \mathrm{a}$ \\
\hline
\end{tabular}

*Médias seguidas de mesma letra minúscula na coluna não diferem entre si pelo teste de Tukey a 5\%.


Figura 4. Teores de P, K, Fe e Zn no substrato em função do percentual de palha de café utilizada na produção de vermicomposto.

Mesmo com a redução observada no teor de $\mathrm{K}$ na segunda avaliação (final do período de digestão) a utilização do vermicomposto como fonte de $\mathrm{K}$ pode ser vantajosa, pois permite que este seja mais prontamente disponibilizado ao solo e às plantas do que seu fornecimento direto como palha de café, a qual demandará um período de tempo longo para liberá-lo.

Quanto aos teores de $\mathrm{P}, \mathrm{Fe}$ e $\mathrm{Zn}$ não houve aumento ou redução decorrente do período de digestão do substrato pelas minhocas. Para o P, estes resultados concordam com Dores-Silva et al. (2011), porém discordam daqueles obtidos por de Tagliari (1995), que observou que os excrementos de minhocas aumentaram de três a onze vezes o teor de fósforo assimilável. No presente trabalho, o aumento no percentual de palha de café utilizada na produção do vermicomposto resultou em queda nas concentrações desses nutrientes, indicando que o fornecimento de $\mathrm{P}$ junto ao solo será maior se utilizado o esterco puro (ARAÚJO et al., 2011). Do ponto de vista do fornecimento de nutrientes para os elementos acima listados, a utilização do vermicomposto parece não ser recomendado. No entanto, seu uso se justifica quando se consideram os benefícios físicos ao solo (SILVA; MENDONÇA, 2007) e o fornecimento conjunto de outros nutrientes.

A porcentagem de $50 \%$ de palha de café no vermicomposto resultou no fornecimento mais equilibrado dos nutrientes, pois apesar de não fornecer o máximo de $\mathrm{N}, \mathrm{K}, \mathrm{Ca}$ e $\mathrm{Cu}$ também não fornecerá o mínimo de $\mathrm{Mg}, \mathrm{S}, \mathrm{Mn}, \mathrm{P}, \mathrm{Fe}$ e Zn. Outro aspecto a se considerar é que a proporção de $50 \%$ palha:esterco já se apresentava pronta, ao final do período de diges- 
tão, com aspecto visual e ao tato adequados, o que ainda não havia ocorrido com as proporções $75 \%$ e $100 \%$ de palha de café, provavelmente, em decorrência da maior relação $\mathrm{C} / \mathrm{N}$ desses tratamentos. Esse aspecto favorece os tratamentos com menor proporção de palha, haja vista o tempo necessário para finalização do vermicomposto ter sido menor.

\section{CONCLUSÃO}

A palha de café não interferiu no incremento populacional das minhocas.

O aumento percentual da palha de café na constituição do vermicomposto aumentou a disponibilidade de $\mathrm{N}, \mathrm{K}$ e $\mathrm{Ca}$ e o de $\mathrm{Cu}$ até o limite com $75 \%$ de palha de café, mas reduziu a disponibilidade de $\mathrm{P}, \mathrm{Mg}, \mathrm{S}, \mathrm{Fe}, \mathrm{Mn}$ e $\mathrm{Zn}$.

Visando o fornecimento médio de nutrientes, a proporção de $50 \%$ de palha de café e $50 \%$ de esterco bovino foi a mais indicada.

A palha de café apresentou potencial de utilização como substrato para produção de vermicomposto em associação com o esterco bovino.

\section{REFERÊNCIAS}

ANTONIOLLI, Z. I. et al. Minhocultura e Vermicompostagem. Santa Maria: UFSM, 2002. 24 p. (Boletim Tecnico $\mathrm{N}^{\mathrm{o}}$ 03)

ARAUJO, A. dos S. et al. Substituição de nitrogênio por esterco bovino na produtividade de forragem e qualidade do solo. Revista Brasileira de Saúde e Produção Animal, Salvador, v. 12, n. 4, p. 852-866, 2011.

ÁVILA, U. Criação de minhocas sem segredo. Guaíba, RS: Editora Agropecuária, 1999. 72 p.

BASSACO, A. C. et al. Caracterização química de resíduos de origem animal e comportamento de Eisenia andrei.Ciência e Natura, Santa Maria, v.37 n.1, p. $45-51,2015$.

BATTIROLA, D.M.; TORRES; V.S.; SCHERER, E.E. Avaliação da compostagem dolixo orgânico e do esterco bovino por diferentes agentes biológicos. Biotemas, Florianópolis, v.11, n.2. p.71-84. 1998.

CALONEGO, J. C. et al. Persistência e liberação de nutrientes da palha de milho, braquiária e labe-labe. Bioscience Journal, Uberlândia, v. 28, n. 5, p. 770$781,2012$.

CAMPITELLI, P.; CEPPI. S. Effects of composting technologies on the chemical and physicochemical properties of humic acids. Geoderma, Amsterdam, v.144, n.1-2, p.325-333, 2008.

CARLESSO, W.; RIBEIRO, R.; HOEHNE, L. Tratamento de resíduos a partir de compostagem e vermicompostagem. Revista Destaques Acadêmicos, Lajeado, v. 3, n. 4, p. 105-110, 2011.

COSTA, F. G; VALERI, S. V. Efeito do esterco bovino no teor e acúmulo de macronutrientes em folhas de Corymbia citriodora. Nucleus, Ituverava, v.9, n.1, p.101-114, 2012 .

CUNHA, C. et al. Substratos alternativos para produção de mudas de alface e couve em sistema orgânico. Scientia Plena, Aracaju,v. 10, n. 11, p. 1-9, 2014.

DORES-SILVA, P. R.; LANDGRAF, M. D.; REZENDE, M. O. de O. Processo de estabilização de resíduos orgânicos: vermicompostagem versus compostagem. Química Nova, São Paulo, v. 36, n. 5, p. 640-645, 2013.

DUARTE, I. N.; PEREIRA, H. S.; KORNDÖRFER, G. H. Lixiviação de potássio proveniente do termopotássio. Pesquisa Agropecuária Tropical, Goiânia, v. 43, n. 2, p. 195-200, 2013.

SILVA, F. C. da. (Ed.) Manual de análises químicas de solos, plantas e fertilizantes. 2. ed. rev. e ampl. Brasília: EMBRAPA INFORMAÇÃO TECNOLÓGICA, 2009, 627p.

ESTAÇÃO METEOROLÓGICA - São Mateus A616. Monitoramento Agrometereológico. Disponível em: http://www.ceunes.ufes.br/estacao/ index2.asp? estação=A616. Acesso em: 05 maio 2012.

FERNANDES, A. L. T. et al. Redução da adubação mineral do cafeeiro com a utilização de palha de café. Coffee Science,Lavras, v. 8, n. 3, p. 324-336, 2013

FIGUEIREDO C. C. et al. Mineralização de esterco de ovinos e sua influência na produção de alface. Horticultura Brasileira, Viçosa, v. 30, n. 1, p. 175 179, 2012.

GARG, V. K.; YADAY, A. Vermicomposting: an effective tool for the management of invasive weed Parthenium hysterophorus. Bioresource Technology, Oxon, v. 102, n. 10, p. 5891-5895, 2011.

LANDGRAF, M. D.; MESSIAS, R. A.; REZENDE, M. O. O. A Importância ambiental da vermicompostagem: vantagem e aplicação. São Carlos: Rima, 2005. 105p.

LANDGRAF, M. D. et al. Characterization of humic acids from vermicompost of cattle manure com- 
posting by 3 and 6 months. Química Nova, São Paulo, v. 22, p. 483- 486, 1999

MARTINEZ, A. A. A grande e poderosa minhoca - manual prático do minhocultor. Guaíba, RS: FUNEP, Editora Agropecuária, 1995. 137 p.

MELO JÚNIOR, H. B. et al. Efeito da ação decompositora da minhoca californiana (Lumbricus rubellus) na composição química de um fertilizante organomineral. Bioscience Journal, Uberlândia, v. 28, Supplement 1, p. 170-178, 2012.

MENEZES, R. S. C.; DA SILVA, T. O. Mudanças na fertilidade de um NeossoloRegolítico após seis anos de adubação orgânica. RevistaBrasileira de Engenharia Agrícola e Ambiental, Campina Grande, v.12, n.3, p.251-257, 2008

MINISTÉRIO DO MEIO AMBIENTE. Manual para implantação de compostagem e de coleta seletiva no âmbito de consórcios públicos. Brasília, DF, 2010. 69 p.

NEUHAUSER, E. F.; LOEHR, R. C.; MALECKI, M. R. The potential of earthworms for managing sewage sludge. In: Edwards., C. A., Neuhauser, E.F. (eds.), Earthworms in Waste and Environmental Management. SPB Academic Publishing BV, The Hague, 1988, p. 9-20.

OTHMAN, N.; IRWAN, J.M.; ROSLAN, M. A. Vermicomposting of Food Waste.International Journal of Integrated Engineering, Johor, v. 4, n. 2, p. 39-48, 2012.

PEREIRA, E. W. L. et al. Produção de vermicomposto em diferentes proporções de esterco bovino e palha de carnaúba. RevistaCaatinga, Mossoró, v. 18 , n. 2, p. 112-116, 2005

RODRIGUES, V. C. et al. Produção de minhocas e composição mineral do vermicomposto e das fezes procedentes de bubalinos e bovinos. Ciência e Agrotecnologia, Lavras. v.27, n.6, p.1409-1418, 2003.

SARDÁ, L. G. et al. Redução da emissão de $\mathrm{CO}_{2}$, $\mathrm{CH}_{4}$ e $\mathrm{H}_{2} \mathrm{~S}$ através da compostagem de dejetos suínos. Revista Brasileira de Engenharia Agrícola e Ambiental, Campina Grande, v. 14, n. 9, p. 10081013, 2010.

SILVA, C. D. et al. Vermicompostagem de lodo de esgoto urbano e bagaço de cana-de-açucar. Revista Brasileira de Engenharia Agrícola Ambiental, Campina Grande, v. 6, n. 3, p. 487-491, 2002.

SILVA, I. R. da; MENDONÇA, E. S. Matéria orgâ- nica do solo. In: NOVAIS, R. F. et al. (Eds.) Fertilidade do Solo. Viçosa: Sociedade Brasileira de Ciências do Solo, 2007. v. 1, cap. 6, p. 276-374.

SILVA, J. J. M. et al. Esterco bovino e potássio na composição mineral de plantas de noni. Ciência Florestal, Santa Maria, v. 24, n. 4, p. 1021-1030, 2014.

SILVA, J. M. da; et al. Mineralização de vermicompostos estimada pela respiração microbiana. Revista Verde de Agroecologia e Desenvolvimento Sustentável, Mossoró, v. 8, n.4, p.132 - 135, 2013.

SILVA, P. R. D. da; LANDGRAF, M. D; REZENDE, M. O. O. Avaliação do potencial agronômico de vermicomposto produzido a partir de lodo de esgoto doméstico. Revista Brasileira de Ciências Agrárias (Agrária), Recife, v. 6, n. 4, p. 565-575, 2011 a.

SILVA, R. F. et al. Caracterizações microbiológicas e químicas em resíduos orgânicos submetidos à vermicompostagem. Revista Brasileira de Agrociência, Pelotas, v. 17, n. 1-4, p. 108-115, 2011 b.

SOUZA, J. L.; REZENDE, P. L. Manual de horticultura orgânica. Viçosa: Aprenda Fácil. 2006. 843 p.

STEFFEN, J. P. K. et al. Utilização de vermicomposto como substrato para produção de mudas de $E$ ucalyptus grandis e Corymbia citriodora. Pesquisa Florestal Brasileira, Colombo, v. 31, n. 66, p. 7582, 2011.

STEVENSON, F. J. Húmus chemistry: gênesis, composition, reactions. New York: John Wiley \& Sons, 1994. 486p.

SUSZEK, M. et al. Uso de água residuária da suinocultura na bioestabilização de resíduos verdes urbanos. Revista Brasileira de Engenharia Agrícola Ambiental. Campina Grande, v. 9, (suplemento), p. 176-180, 2005

TAGLIARI, P. S. Minhoca: a grande aliada da agricultura. Agropecuária Catarinense, Florianópolis, v. 8, n. 1, p. 11-14, 1995.

TRIPATHI, G.; BHARDWAJ, P. Comparative studies on biomass production, life cycles and composting efficiency of Eisenia fetida (Savigny) and Lampito mauritti (Kinberg). Bioresource Technology, Oxon, v. 92, n.3, p. 275-283, 2004

ZOCA, S. M. Avaliação da liberação de potássio por resíduos do benefício de café. $2012.57 \mathrm{f}$. Dissertação (Mestrado em Agronomia) - Universidade Estadual Paulista, Faculdade de Ciências Agronômicas, Botucatu, 2012 